\title{
Fetal Ovarian Cyst Torsion: Antenatal Evaluation and Management
}

Necip Cihangir YILANLIOĞLU' ${ }^{1}$ Altuğ SEMiZ1', Yaşam Kemal AKPAK ${ }^{2,8}$, Nüvit SARIMURAT ${ }^{3}$, Ercan TUTAK ${ }^{4}$,

Yasemin ÇEKMEZ ${ }^{5}$, Meltem ÖZBEN ${ }^{6}$, Nilay KARACA

${ }^{1}$ Fetal Medicine Unit, Memorial Şişli Hospital, İstanbul, Turkey

${ }^{2}$ Clinic of Gynecology and Obstetrics, Ankara Mevki Military Hospital, Ankara, Turkey

${ }^{3}$ Clinic of Pediatric Surgery, Memorial Şişli Hospital, İstanbul, Turkey

${ }^{4}$ Neonatal İntensive Care Unit, Memorial Şişli Hospital, İstanbul, Turkey

${ }^{5}$ Clinic of Gynecology and Obstetrics, Ümraniye Training and Research Hospital, İstanbul, Turkey

${ }^{6}$ Clinic of Gynecology and Obstetrics, Balat Private Hospital, İstanbul, Turkey

${ }^{7}$ Clinic of Gynecology and Obstetrics, Bezmialem University Hospital, İstanbul, Turkey

${ }^{8}$ Clinic of Gynecology and Obstetrics, Dışkapı Yıldırım Beyazıt Training and Research Hospital, Ankara, Turkey

\section{ABSTRACT}

Routine antenatal care is rendered more effective if some extra care is spent on the general anatomical development of the fetus even in the last few weeks approaching term, when some previously unsuspected pathologies can be detected and appropriately managed. In this case, we present the case of a patient in her $35^{\text {th }}$ gestational week. The fetus was suspected to have an ovarian cyst, and the patient was therefore referred to our hospital. By means of Doppler ultrasound examination, a fetal ovarian cyst torsion was diagnosed, and delivery was expedited to enable the pediatric surgeon to operate on the newborn. The diagnosis was confirmed at the operation, and the ovary was salvaged with a successful cystectomy.

Keywords: Fetal ovarian cyst, prenatal diagnosis, fetal abdominal mass, ultrasound scan, ovarian torsion

\section{Introduction}

Diagnosis of fetal diseases in the antenatal period is crucial for fetal health and survival (1). The rate of fetal ovarian cysts, which is clinically significant, is 1 in 2500 live births. Although cysts of less than $2 \mathrm{~cm}$ in diameter is considered normal, continuous evaluation through ultrasonographic follow-ups is required. They should be distinguished from intestinal duplication cysts, lymphangiomas, cystic meconium peritonitis, neuroblastomas, cystic teratomas, renal cystic dysplasia, mesenteric cysts, omentum cysts, and choledochal cysts in definitive diagnoses (2). Simple ovarian cysts that are considered normal are formed due to the effect of maternal estrogen, increased placental hormones, and fetal gonadotropins. Diseases such as maternal diabetes mellitus, $\mathrm{Rh}$ isoimmunization, and fetal hypothyroidism may increase the formation of ovarian cysts by increasing fetal gonadotropin levels (3). Fetal ovarian cysts, most of which are antenatally detected, spontaneously regress a few months after birth. These cysts are mostly diagnosed during the third trimester due to the effect of the hypothalamic-pituitary-gonadal pathway, which is completed in the 29th gestational week (4). Although fetal ovarian cysts can cause fetal anemia, compression, or rupture during the antenatal period, the most common complication is intracystic hemorrhage, followed by torsion (5). Cysts are diagnosed as simple or complex through ultrasonography in the antenatal period. Simple cysts are thin-walled and anechoic, whereas complex cysts are septated and contain particulate or solid areas. Despite the numerous case series in the literature, there is still no clear consensus on its management. After diagnosis, a good evaluation and sound criteria are needed for antenatal intervention or birth decision. Although the tuba uterina can tolerate not being supplied with blood up to 90 degrees of rotation, if this process is not intervened, it may result in ovarian loss, adhesion in the organs of the abdomen, and 
infant death with their necrosis (3). In this case report, we aimed to evaluate the management of a torsioned fetal ovarian cyst detected during the antenatal period in light of the literature.

\section{Case Report}

This was the second pregnancy for a 40-year-old patient with a history of one Cesarean birth. There were no other significant features in her medical history. No anomalies were detected in antenatal follow-ups, including a second level ultrasonography performed at another center, and the patient was evaluated at normal limits. In the obstetric ultrasound performed in the $35+2$ weeks of pregnancy, the estimated fetal weight was $2780 \mathrm{~g}$ and a heterogeneous echogenic ovarian cyst with a diameter of $4.14 \times 3.46 \mathrm{~cm}$ was observed in the left adnexal area below the stomach cavity (Figure 1). A suspicious weak flow was also observed in the mass, which was evaluated with Doppler ultrasonography. No other features or abnormalities were detected except that the measurement of abdominal circumference was found 1 week ahead. A fetal ovarian cyst torsion was diagnosed. Due to the significant decrease in the Doppler flow, Cesarean section was proposed to the family considering the fact that the week and weight of the infant were appropriate in order to recover the ovary. With the family's consent, Cesarean delivery was performed after taking the necessary consents and informing pediatric surgery. A baby girl weighing $2790 \mathrm{~g}$ was delivered. Abdominal ultrasonography with Doppler was performed for the baby and the same intrauterine findings were observed. The baby underwent surgery. A central transverse incision was made for entry. The torsioned ovary cyst and adnex were observed in the left adnexal area (Figure 2). The cyst was de-torsioned. Its color got better. It was stripped from the capsule and sent to pathology. The tube and ovary were observed to be supplied with blood again and the abdomen was closed. The baby was observed postoperatively for 1 day in the neonatal intensive care unit, after which she was taken to the service and discharged 2 days later as healthy. Pathology tests reported a calcifying torsioned ovarian cyst containing previous hemorrhage and fibrin. Ovarian circulation and structure were observed as normal through the transabdominal ultrasonography on postoperative day 7 .

\section{Discussion}

The prenatal and postnatal management of ovarian cysts is still unclear. There are those who find surgical intervention as well as follow-up through ultrasonography with a waitand-see method as effective and reasonable. Ovarian cyst was diagnosed in 33.6 weeks of gestation in a series in which 73 fetuses were examined (3). In another series of 82 cases, it was diagnosed in the $32^{\text {nd }}$ gestational week on average (5). In our case, diagnosis was made in the third trimester in the $35^{\text {th }}$ gestational week. Bilateral appearance is very rare. Fetal ovarian cysts, which are usually unilateral, are observed twice as often on the right side compared with the left side (5). In our case, it was observed unilaterally on the left.

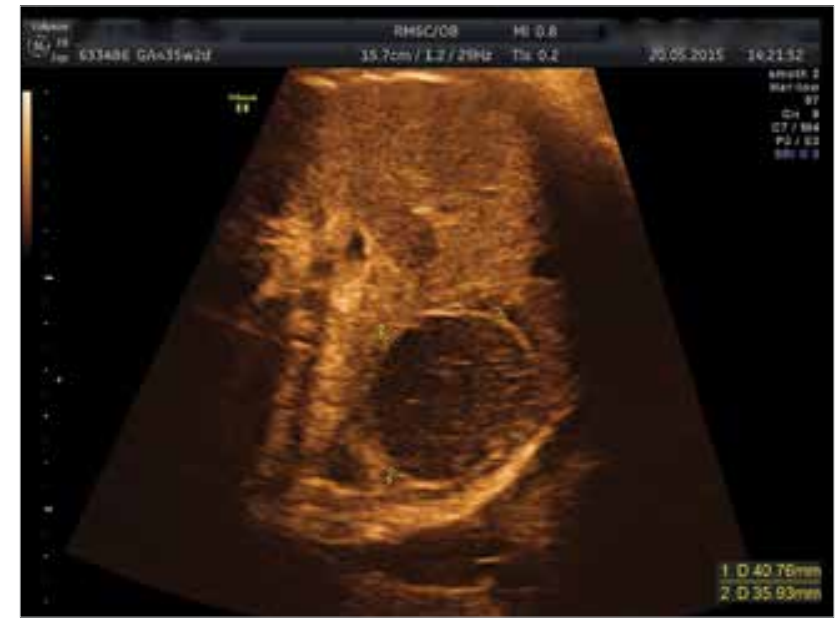

Figure 1. Fetal left ovarian cyst torsion detected by prenatal ultrasound and confirmed after surgery

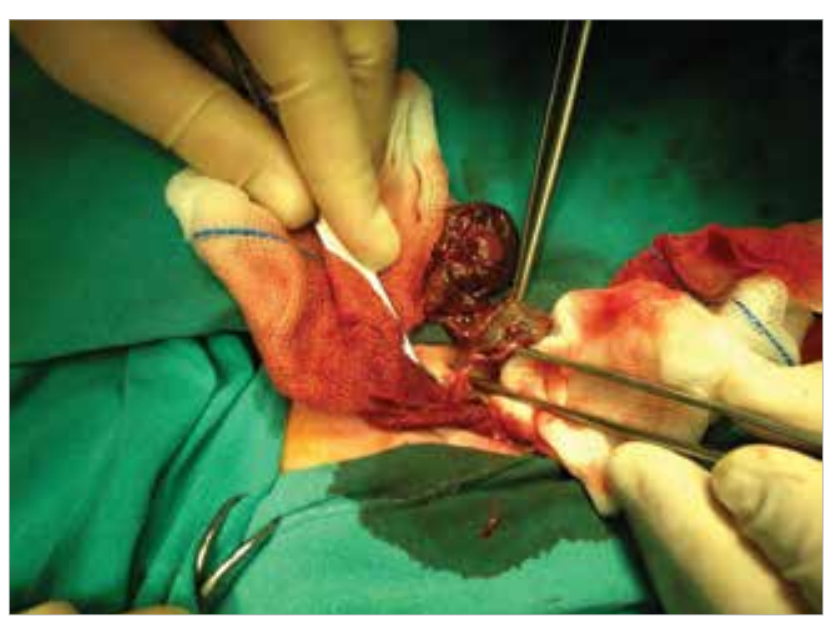

Figure 2. Ovarian cyst that was postnatally detorsioned and whose capsule was stripped

Although accurate preoperative identification rate of ovarian cyst torsions in adults is $66 \%$, it is very difficult to identify them in intrauterine fetuses $(6,7)$. In fact, measuring the cyst peduncle is a more effective method of predicting the torsion than measuring the size of the cyst. However, as it can only be measured during operation and predicting with ultrasonography is difficult, it is an unusable method $(8,9)$. Fetal cysts are found in the abdomen, not in the pelvis, and in our case, it was detected under the stomach.

In a study that prospectively examined fetal ovarian cysts for 7 years, $76 \%$ of the cases with cysts of less than $5 \mathrm{~cm}$ in diameter spontaneously regressed, and the average cyst size of the other torsioned cases were observed to be $4.4 \mathrm{~cm}$. In the same study, an aspiration procedure was performed without complication in 14 cases with cysts of more than $5 \mathrm{~cm}$ in diameter, and only 2 cases presented with postnatal torsion. The others were observed to recover completely. This study argues that aspiration can prevent torsion and follow-up is possible (3). 
In another series, it was found that aspiration did not prevent torsion in simple cysts and was not statistically significant (5). Cysts that were observed to be simple can become hemorrhagic or complex cysts after they exceed $4 \mathrm{~cm}$. Hemorrhagic cysts usually have a tendency to undergo torsion (5). Even if hemorrhagic cysts are followed antenatally, the majority of them are operated upon in the postpartum period. In a series of 67 patients, $90 \%$ of complex cysts were found torsioned during the operation (10). While simple cysts are usually followed up, there are studies suggesting that the dimensions are not sufficient for the risk of torsion or hemorrhage and that small cysts may also be exposed to these complications (5). The use of cyst size for the prediction of torsion was also found statistically insignificant in a study. In this study, no predictive method for spontaneous resolution or for torsion was found (10). Although some authors suggest that fetuses with lung maturity should be delivered and de-torsioned, it is not generally accepted in cases wherein torsion is identified or predicted because they are not bilateral ovarian cysts (11). While the sudden turn of closely-monitored fetuses from anechoic cyst to hemorrhagic cyst is an important parameter for torsion, it is difficult to recover the ovary after 1-2 weeks of delay for the intervention (5). In our case, the cyst was larger than $4 \mathrm{~cm}$ in diameter and had a complex appearance. Torsion was predicted based on Doppler findings.

The reasons that make surgery predominant are the torsion complication, the suspicion of a tumoral mass (though almost all of them are benign until 1 year of age), the fear of leaving necrotic tissue after auto-amputation, and the complication of intestinal obstruction $(5,12,13)$. Those who recommend the expectant method argue that the postnatal operation performed with the prenatal diagnosis will not be effective, anesthesia taken during the first six months of life may have serious toxic effects, and malignancy in the first year is almost impossible (6). In a study following a waitand-see protocol; a single ovary was visualized at a rate of $40 \%$ and both ovaries were observed at $60 \%$ in the followups of 41 infants with complex ovarian cysts through ultrasonographic examinations that lasted up to adolescence. However, all cysts were found to be smaller than $4 \mathrm{~cm}$ in diameter in these patients (6).

In a series of 25 cases, one postnatal torsion was observed in an expectant regimen and oophorectomy was performed in that patient. However, intact ovary tissue was observed in the pathology. Therefore, de-torsion followed by cystectomy is recommended (2). In our case, de-torsion and then cyst capsule extirpation were performed. Although laparotomy is generally preferred, there are also studies showing that laparoscopy is effective with two ports (4). Laparotomy was preferred in our case.

\section{Conclusion}

Although fetal ovarian cysts are pathologies that may spontaneously disappear during medical follow-ups, they should be be determined according to the changes in their structures and sizes. If torsion can be diagnosed intrauterinely, the fetal life and ovaries can be saved by early surgical intervention.

Informed Consent: Written informed consent was obtained from the patient.

Peer-review: Externally peer-reviewed.

Author Contributions: Concept - N.C.Y., A.S.; Design - N.C.Y., A.S., Y.K.A.; Supervision - N.C.Y., A.S., Y.K.A., N.S., E.T., Y.Ç., M.Ö., N.K.; Funding - N.C.Y., A.S., Y.K.A., N.S., E.T., Y.Ç., M.Ö., N.K.; Materials N.C.Y., A.S., Y.K.A., N.S., E.T., Y.Ç., M.Ö., N.K.; Data Collection and/ or Processing - N.C.Y., A.S., Y.K.A., N.S., E.T., Y.Ç., M.Ö., N.K.; Analysis and/or Interpretation - N.C.Y., A.S., Y.K.A., N.S., E.T., Y.Ç., M.Ö., N.K.; Literature Review - N.C.Y., A.S., Y.K.A., N.S., E.T., Y.Ç., M.Ö., N.K.; Writing - N.C.Y., A.S., Y.K.A., N.S., E.T., Y.Ç., M.Ö., N.K.; Critical Review - N.C.Y., A.S., Y.K.A., N.S., E.T., Y.Ç., M.Ö., N.K.

Conflict of Interest: No conflict of interest was declared by the authors.

Financial Disclosure: The authors declared that this study has received no financial support.

\section{References}

1. Yılanlığlu C, Semiz A, Akpak YK. Prenatal treatment of fetal goitrous hypothyroidism by intraamniotic thyroxine. Medical Bulletin of Zeynep Kamil 2013; 44: 155-8.

2. Papic JC, Billmire DF, Rescorla FJ, Finnell SM, Leys CM. Management of neonatal ovarian cysts and its effect on ovarian preservation. J Pediatr Surg 2014; 49: 990-3; discussion 993-4. [CrossRef]

3. Bagolan P, Giorlandino C, Nahom A, Bilancioni E, Trucchi A, Gatti C, et al. The management of fetal ovarian cysts. J Pediatr Surg 2002; 37: 25-30. [CrossRef]

4. Tseng D, Curran TJ, Silen ML. Minimally invasive management of the prenatally torsed ovarian cyst. J Pediatr Surg 2002; 37: 1467-9. [CrossRef]

5. Galinier P, Carfagna L, Juricic M, Lemasson F, Moscovici J, Guitard J, et al. Fetal ovarian cysts management and ovarian prognosis: a report of 82 cases. J Pediatr Surg 2008; 43: 2004-9. [CrossRef]

6. Cesca E, Midrio P, Boscolo-Berto R, Snijders D, Salvador L, D'Antona $\mathrm{D}$, et al. Conservative treatment for complex neonatal ovarian cysts: a long-term follow-up analysis. J Pediatr Surg 2013; 48: 510-5. [CrossRef]

7. Mashiach S, Bider D, Moran O, Goldenberg M, Ben-Rafael Z. Adnexal torsion of hyperstimulated ovaries in pregnancies after gonadotropin therapy. Fertil Steril 1990; 53: 78-80. [CrossRef]

8. Sakala EP, Leon ZA, Rouse GA. Management of antenatally diagnosed fetal ovarian cysts. Obstet Gynecol Surv 1991; 46: 407-14. [CrossRef]

9. Nakamura M, Ishii K, Murata M, Sasahara J, Mitsuda N. Postnatal outcome in cases of prenatally diagnosed fetal ovarian cysts under conservative prenatal management. Fetal Diagn Ther 2015; 37: 129-34. [CrossRef]

10. Monnery-Noché ME, Auber F, Jouannic JM, Bénifla JL, Carbonne B, Dommergues $\mathrm{M}$, et al. Fetal and neonatal ovarian cysts: is surgery indicated? Prenat Diagn 2008; 28: 15-20. [CrossRef]

11. Meizner I, Levy A, Katz M, Maresh AJ, Glezerman M. Fetal ovarian cysts: prenatal ultrasonographic detection and postnatal evaluation and treatment. Am J Obstet Gynecol 1991; 164: 874-8. [CrossRef]

12. Schultz KA, Sencer SF, Messinger Y, Neglia JP, Steiner ME. Pediatric ovarian tumors: a review of 67 cases. Pediatr Blood Cancer 2005; 44: 167-73. [CrossRef]

13. Ozcan HN, Balci S, Ekinci S, Gunes A, Oguz B, Ciftci AO, et al. Imaging findings of fetal-neonatal ovarian cysts complicated with ovarian torsion and autoamputation. AJR Am J Roentgenol 2015; 205: 185-9. [CrossRef] 